archives

of thermodynamics

Vol. 36(2015), No. 2, 75-84

DOI: $10.1515 /$ aoter-2015-0016

\title{
Comparative investigation of working fluids for an organic Rankine cycle with geothermal water
}

\author{
YAN-NA LIU ${ }^{a}$ \\ SONG XIAO ${ }^{b 1}$ \\ a Faculty of Chemical Engineering, Kunming University of Science and \\ Technology, Kunming, 650500, China \\ ${ }^{b}$ Faculty of Metallurgical and Energy Engineering, Kunming University \\ of Science and Technology, Kunming, 650093, China
}

\begin{abstract}
In this paper, the thermodynamic investigation on the use of geothermal water $\left(130^{\circ} \mathrm{C}\right.$ as maximum) for power generation through a basic Rankine has been presented together with obtained main results. Six typical organic working fluids (i.e., R245fa, R141b, R290, R600, R152a, and 134a) were studied with modifying the input pressure and temperature to the turbine. The results show that there are no significant changes taking place in the efficiency for these working fluids with overheating the inlet fluid to the turbine, i.e., efficiency is a weak function of temperature. However, with the increasing of pressure ratio in the turbine, the efficiency rises more sharply. The technical viability is shown of implementing this type of process for recovering low temperature heat resource.
\end{abstract}

Keywords: Geothermal water; Energy efficiency; Organic Rankine cycle

\section{Introduction}

Using fossil fuels can lead to some serious environment problems such as global warming, pollution, and ozone depletion. In recent years, because renewable energy sources can avoid environmental problems and refresh

\footnotetext{
${ }^{1}$ Corresponding Author. E-mail: xsong@kmust.edu.cn
} 
themselves in the natural process, they have currently gained great importance. It is required to utilize new energy suitable for power generation without causing serious environmental pollution. With the new technologies developing, low-grade heat sources can be converted to appropriate energy type. Solar heat, waste heat, and geothermal energy are typical examples for low-grade heat sources with their available temperatures ranging between $60^{\circ} \mathrm{C}$ and $200^{\circ} \mathrm{C}[1]$.

Geothermal resources can be found anywhere in the world, and geothermal heat sources vary in temperature from $50^{\circ} \mathrm{C}$ to $350^{\circ} \mathrm{C}[2-4]$. There are two categories technologies for geothermal energy utilization, i.e., direct uses for space heating and cooling, industrial processes and electric energy production [5-10]. Three major types of electric generation plants from geothermal sources are operating today: dry-steam plants, flash-steam plants, binary cycle plants where binary and combined flash/binary plants are relatively new designs [11]. As a renewable energy source, low-temperature geothermal heat sources have a very large potential [12-14]. Due to the low temperature, the electricity conversion efficiency is low. Therefore, when the temperature of the geothermal water is less than $200^{\circ} \mathrm{C}$, binary cycle method may be most suitable and cost-effective for generation of electricity [12].

In a binary cycle power plant, a secondary working fluid, usually an organic fluid, has a lower boiling point and higher vapor pressure than water at a given temperature $[15,16]$. Traditionally, binary plants have been small modular units varying in size from a few hundred kilowatts to several megawatts [17]. Organic fluid plays an important role in the cycle, since selection of organic working fluid affects considerably the system performance. There are various examples of papers regarding selection of the organic working fluid for the cycle [18-29].

In this paper, the inlet and output pressure to the turbine are parameterized for each studied fluid at a given temperature and, therefore, the ratio of inlet pressure to turbine to discharge pressure of turbine $\left(P_{1} / P_{2}\right)$ is maintained equal to 1.5, 2.5 and 3.0, seeking a minimum, an intermediate and a maximum that were common to all fluids. The results obtained allow determining whether the rise of the inlet pressure to the turbine centributes to increase or decrease of the cycle performance qualitatively, but, similarly, allows realizing in how much increase or decrease this efficiency. 


\section{$2 \quad$ Theoretical process}

The principle of operation of conventional and organic Rankine cycle is same, while the difference is that the organic Rankine cycle uses an organic agent as the working fluid. A pump pressurizes the liquid fluid, and it is injected in the evaporator to produce vapor that is expanded in a turbine connected to a generator; finally, the exit vapor is condensed, starting the new cycle (Fig. 1).

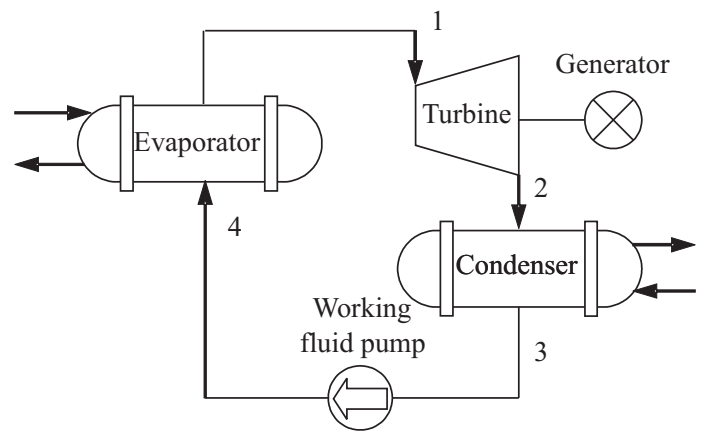

Figure 1: Schematics diagram of the Rankine cycle.

The analysis assumes steady state conditions, no pressure drop or heat loss in the evaporator. The cycle's total energy efficiency is given by

$$
\eta=\frac{W_{\text {turbine }}-W_{\text {pump }}}{Q_{\text {evaporator }}}
$$

where $\eta$ is the total energy efficiency, $W_{\text {turbine }}$ is the mechanical work of turbine, $W_{\text {pump }}$ is the mechanical work of the pump, and $Q_{\text {evaporator }}$ is the quantity of heat of heat exchanger defined as follows

$$
W_{\text {turbine }}=h_{1}-h_{2}
$$

where $h_{1}$ and $h_{2}$ are enthalpies of the working fluid at state 1 and 2 of the cycle,

$$
W_{\text {pump }}=h_{4}-h_{3},
$$

where $h_{3}$ and $h_{4}$ are enthalpies of the working fluid at state 3 and 4 of the cycle, and

$$
Q_{\text {evaporator }}=h_{1}-h_{4}
$$


In the heating process, overheating of the inlet fluid to the turbine, $T_{1}$, is considered from the condition of saturated steam up to its critical temperature. The condensation temperature of working fluid, $T_{3}$, is equal to $35^{\circ} \mathrm{C}$. The discharge pressure of the turbine, $P_{2}$, is equal to the saturation pressure of the fluid in liquid state, $P_{3}$, to the temperature $T_{3}=35^{\circ} \mathrm{C}$, while the inlet pressure to the turbine, $P_{1}$, maintains the ratio $P_{1} / P_{2}$ equal to 1.5 , 2.5 and 3.0. In our study, the Engineering Equation Solver (EES) software [31] was used in the analysis of the thermodynamics of the cycle.

\section{Results and discussion}

According to the assumptions presented in Section 2, six typical organic working fluids, i.e., R245fa, R141b, R290, R600, 152a, and 134a (general properties are given in Tab. 1.) with constant $P_{1} / P_{2}$ ratio have been studied, and the results obtained on the cycle efficiency by increasing the inlet temperature to the turbine $T_{1}$ were shown in Fig. $2(\mathrm{a}-\mathrm{f})$.

Table 1: Characteristics of six typical organic working fluids.

\begin{tabular}{|l|c|c|c|c|}
\hline Fluid & Fluid type & Molecular $(\mathrm{g} / \mathrm{mol})$ & $P_{c r}(\mathrm{MPa})$ & $T_{c r}\left({ }^{\circ} \mathrm{C}\right)$ \\
\hline R245fa & dry & 134.05 & 3.65 & 153.85 \\
\hline R141b & dry & 116.95 & 4.21 & 204.25 \\
\hline R290 & wet & 44.10 & 4.25 & 96.55 \\
\hline R600 & dry & 58.12 & 3.80 & 151.85 \\
\hline R152a & wet & 66.05 & 4.52 & 113.15 \\
\hline R134a & isentropic & 102.03 & 4.06 & 100.95 \\
\hline
\end{tabular}

In Fig. 3 , the results on the $\eta$ of the cycle by increasing the $T_{1}$ at a constant $P_{1} / P_{2}$ ratio for six typical fluids were presented. To achieve a better visual comparison in the same graph, only the pressure ratio and each one of the three ratios were analyzed. It can be obviously found that when $P_{1} / P_{2}=1.5$ (which is the lowest of those studied, see Fig. 3a), with the increasing of the temperature $T_{1}$, the efficiency, $\eta$, of six typical organic working fluids rarely change. It implies that the efficiency, $\eta$, is a weak function of temperature $T_{1}$, and overheating the inlet fluid to the turbine does not cause a significant change in the efficiency, $\eta$.

Nevertheless, with the increasing of the ratio $P_{1} / P_{2}$, obtained are much higher values of the efficiency, $\eta$, for all six fluids as shown in Fig. 3b,c. With 

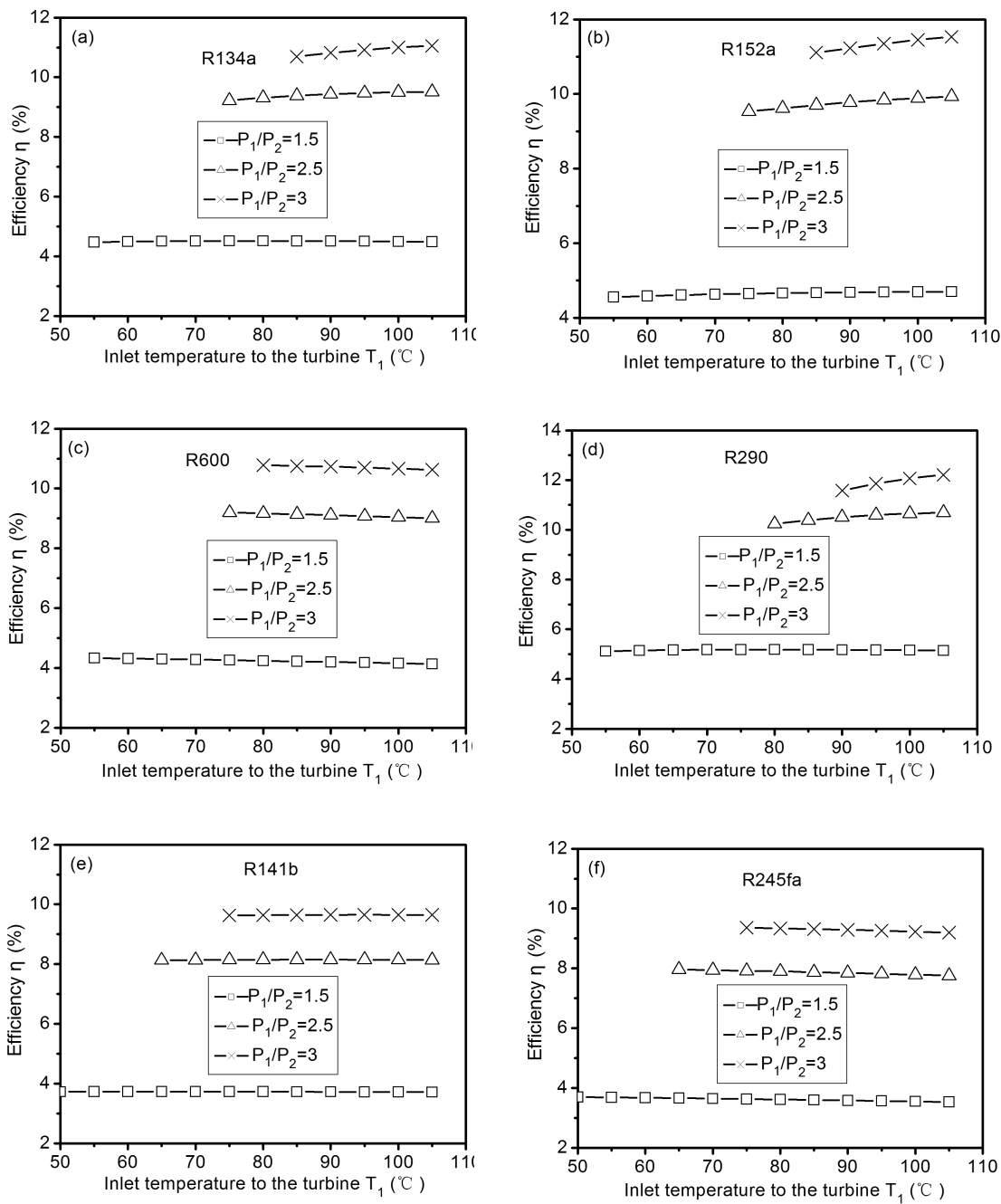

Figure 2: Influence of the inlet temperature to the turbine, $T_{1}$, on the overall efficiency of the cycle with constant $P_{1} / P_{2}$ ratio for: R134a (a), R152a (b), R600 (c), R290 (d), R141b (e), R245fa (f), respectively.

the increasing of the inlet temperature to the turbine, this effect increases more steeply, i.e., for the greater pressure ratio studied $\left(P_{1} / P_{2}=3.0\right)$.

It is interesting to indicate that Fig. 3 also shows that with the pressure ratio fixed and for the temperature range approximately between $80^{\circ} \mathrm{C}$ and $105^{\circ} \mathrm{C}, \mathrm{R} 600$ offers the best performance, by contrast that the efficiency of 

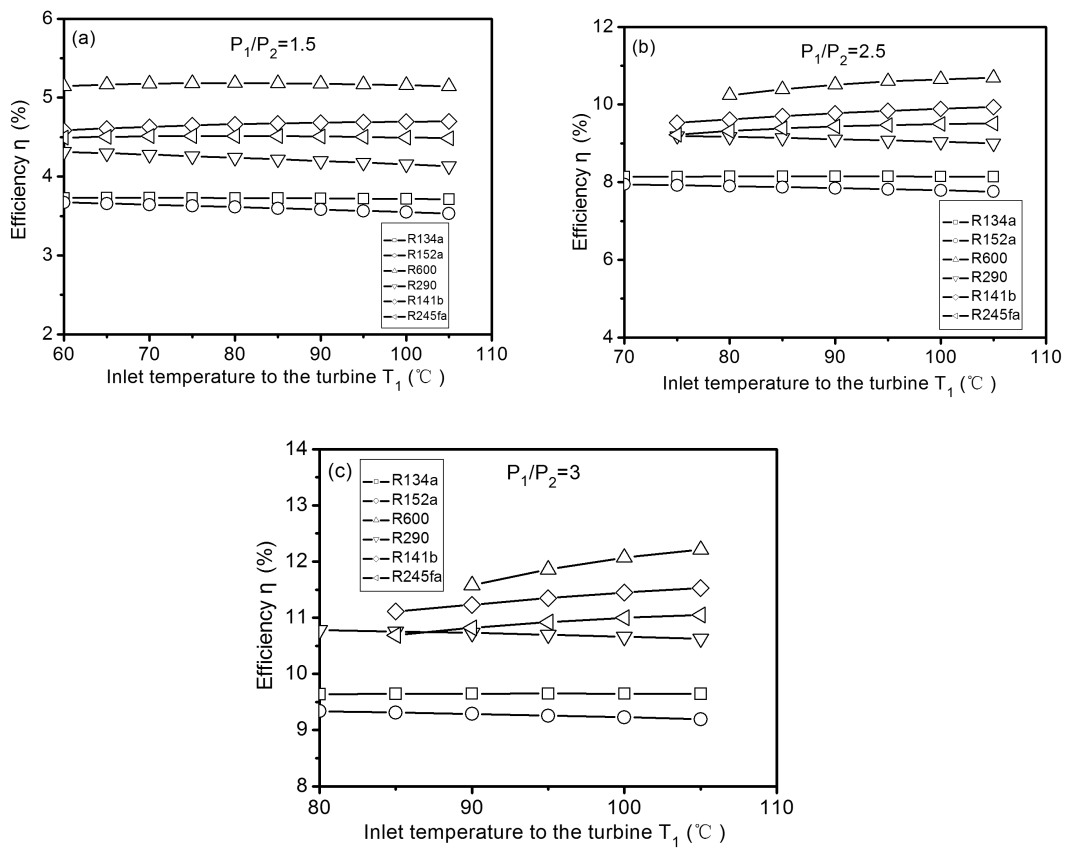

Figure 3: Influence of the input temperature to the turbine, $T_{1}$, on the total efficiency of the cycle with a constant ratio $P_{1} / P_{2}=1.5$ (a), 2.5 (b) and 3.0 (c), respectively.

R152a is the lowest. For the R134a, which is an isentropic fluid, it remains unchanged.

It can be observed that with the increasing pressure ratio, the efficiency of the system raises for all six fluids (see Fig. 4). However, when the pressure ratio $P_{1} / P_{2}=1.5$ or $P_{1} / P_{2}=2.5$, with higher temperature $T_{1}$, the efficiency of the system is rarely changed, and when the pressure ratio $P_{1} / P_{2}=3$, the efficiency of the system increases with the increasing of temperature $T_{1}$.

In Fig. 5, the efficiency of the system enhances with the increase of the pressure ratio for all the fluids used at a constant $T_{1}$ shown. The six fluids were studied for a single inlet temperature to the turbine, $T_{1}$, and each of the two was studied at 90 and $100^{\circ} \mathrm{C}$ for a better visual comparison. Higher $P_{1}$ increases both the net work as the evaporator heat that leads to an improvement in the efficiency of the system. However, the increase in the net work is higher than that in the heat of the evaporator. 

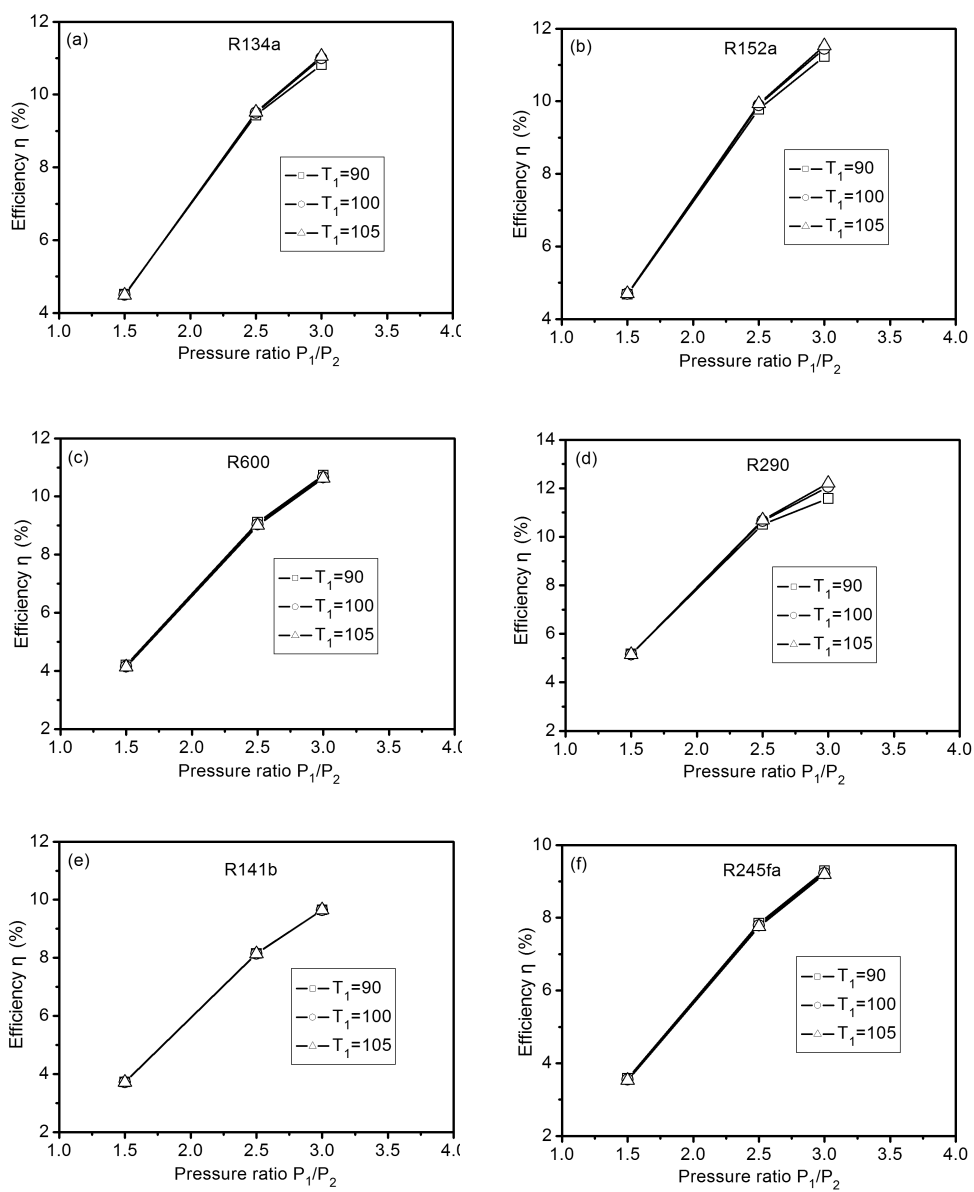

Figure 4: Influence of the $P_{1} / P_{2}$ ratio on the overall efficiency of the cycle, with constant inlet temperature to the turbine, $\mathrm{T}_{1}$, for R134a (a), R152a (b), R600 (c), R290 (d), R141b (e), R245fa (f), respectively.

\section{Conclusions}

In this paper, the thermodynamic investigation on the use of geothermal water $\left(130^{\circ} \mathrm{C}\right.$ as maximum) for power generation through a basic Rankine cycle has been presented. Based on the simulations carried out, it can be mentioned that overheating the inlet fluid to the turbine does not cause a significant change in the overall efficiency of the cycle, since the conclusion can be obtained that the system's efficiency performed a weak function of 
temperature. Interestingly, with the increasing of the pressure ratio in the turbine, much larger values of efficiency are obtained and also, as the inlet temperature to the turbine rising, the efficiency increases more sharply.
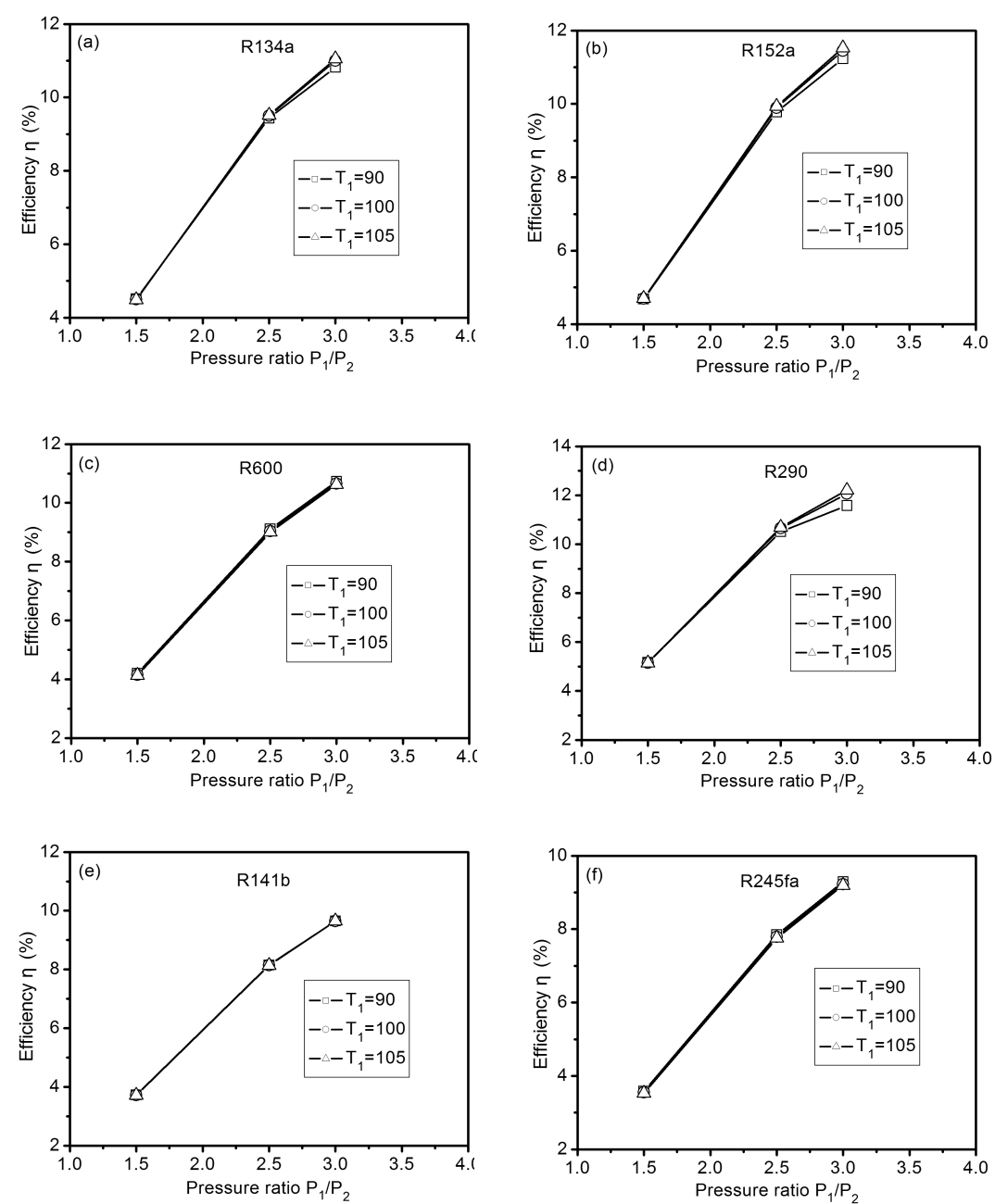

Figure 5: Influence of the ratio $\mathrm{P}_{1} / \mathrm{P}_{2}$ on the total efficiency of the cycle with a constant input temperature to the turbine $T_{1}=90^{\circ} \mathrm{C}$ (a) and $100{ }^{\circ} \mathrm{C}(\mathrm{b})$, respectively.

Acknowledgements Authors gratefully acknowledge the thoughtful comments and suggestions of anonymous reviewers for the improvement of 
the manuscript. Yan-na Liu acknowledges the support of item founded by National Natural Science Foundation (Grant No. 21301079 and No. 51206071), Applied Basic Research Program of Yunnan Province Science and Technology Department Project (2011FZ050).

Received 4 August 2014

\section{References}

[1] Yamamoto T, Furuhata T, Arai N.: Design and testing of the Organic Rankine Cycle. Energy 26(2001), 3, 239-51

[2] Hettiarachchi H.D.M., Golubovic M., Worek W.M., Ikegami Y.: Optimum design criteria for an organic Rankine cycle using low-temperature geothermal heat sources. Energy 3(2007), 9, 1698-1706.

[3] BARBIER E.: Nature and technology of geothermal energy: a review. Renew Sust. Energ. Rev. 1(1997), (1-2), 1-69.

[4] BARBIER E.: Geothermal energy technology and current status: an overview. Renew. Sust. Energ. Rev. 6(2002), 1-2, 3-65.

[5] Ozgener L., Hepbasli A., Dincer I.: Performance investigation of two geothermal district heating systems for building applications: energy analysis. Energ. Build. 38(2006), 286-92.

[6] Ozgener O., Hepbasli A., Ozgener L.: A parametric study on the exergoeconomic assessment of a vertical ground coupled (geothermal) heat pump system. Build. Environ. 42(2007), 1503-1509.

[7] Ozgener L., Ozgener O.: Monitoring of energetic and exergetic performance analysis of Salihli Geothermal District Heating System. J. Energy Resour. Technol. ASME 130(2008), 022302.

[8] Ozgener L., Ozgener O.: Monitoring of energy exergy efficiencies and exergoeconomic parameters of Geothermal District Heating Systems (GDHSs). Appl. Energ. 86(2009), 1704-1711.

[9] Ozgener O., Ozgener L.: Exergoeconomic analysis of an underground air tunnel system for greenhouse cooling system. Int. J. Refrig. 33(2010), 995-1005.

[10] Ozgener O., Ozgener L., Goswami D.Y.: Experimental prediction of total thermal resistance of a closed loop EAHE for greenhouse cooling system. Int. Commun. Heat Mass 38(2011), 711-716.

[11] Kanoglu M.: Exergy analysis of a dual-level binary geothermal plant. Geothermics 31(2002),709-724.

[12] Walraven D., Laenen B., D'haeseleer W.: Comparison of thermodynamic cycles for power production from low-temperature geothermal heat sources. Energ. Convers. Manage. 66(2013), 220-233.

[13] Tester J., Anderson B., Batchelor A., Blackwell D., DiPippo R., Drake E. et al.: The future of geothermal energy: impact of enhanced geothermal systems (EGSs) on the United States in the 21st century. Science 2006. 
[14] Paschen H., Oertel D., Grünwald R.: Möglichkeiten geothermischer Stromerzeugung in Deutschland. TAB Arbeitsbericht 84.

[15] YARI M.: Exergetic analysis of various types of geothermal power plants. Renew. Energ. 35(2010), 112-121.

[16] Gu Z., Sato S.: Performance of supercritical cycles for geothermal binary design. Energ. Convers. Manage. 43(2002), 961-971.

[17] Guo T., Wang H.X., Zhang S.J.: Selection of working fluids for a novel low temperature geothermally-powered ORC based cogeneration system. Energ. Convers. Manage. 52(2011), 2384-2391.

[18] Andersen W.C., Bruno T.J.: Rapid screening of fluids for chemical stability in organic Rankine cycle applications. Ind. Eng. Chem. 44(2005), 5560-5566.

[19] Maizza V., Maizza A.: Unconventional working fluids in organic Rankine-cycles for waste energy recovery systems. Appl. Thermal. Eng. 21(2001), 381-390.

[20] Xiao S., Wu S., Zheng D.: Slagwashing water of blast furnace power station with supercritical organic Rankine cycle. J. Cent. Univ. 20(2013), 737-741.

[21] Tchanche B.F., Papadakis G., Lambrinos G., Frangoudakis A.: Fluid selection for a low-temperature solar organic Rankine cycle. Appl. Therm. Eng. 29(2009), 2468-2476.

[22] Lemort V., Quollin S. Cuevas, C., Lebrun J.: Testing and modeling a scroll expander integrated into an organic Rankine cycle. Appl. Therm. Eng. 29(2009), 3094-3102.

[23] Chen H., Goswami D.Y., Stefanakos E.K.: A review of thermodynamic cycles and working fluids for the conversion of low-grade heat. Renew. Sust. Energ. Rev. 14(2010), 3059-3067.

[24] Bianchi M., De Pascale A.: Bottoming cycles for electric energy generation: parametric investigation of available and innovative solutions for the exploitation of low and medium temperature heat sources. Appl. Energ. 88(2011), 1500-1509.

[25] Chacartegui R., Sánchez D., Muńoz J.M., Sánchez T.: Alternative ORC bottoming cycles for combined cycle power plants. Appl. Energ. 86(2009), 21622170.

[26] Lai N.A., Wendland M., Fischer J.: Working fluids for high-temperature organic Rankine cycles. Energy 36(2011), 199-211.

[27] Roy J.P., Mishra M.K., Misra A.: Performance analysis of an organic Rankine cycle with superheating under different heat source temperature conditions. Appl. Energ. 88(2011), 2995-3004.

[28] Wang E.H., Zhang H.G., Fan B.Y., Ouyang M.G., Zhao Y., Mu Q.H.: Study of working fluid selection of organic Rankine cycle (ORC) for engine waste heat recovery. Energy 36(2011), 3406-3418.

[29] YARI M.: Exergetic analysis of various types of geothermal power plants. Renew. Energ. 35(2010), 112-121.

[30] ZióŁkowski P.,Mikielewicz D., Mikielewicz J.: Increase of power and efficiency of the $900 \mathrm{MW}$ supercritical power plant through incorporation of the ORC. Arch. Thermodyn. 34(2013), 4, 51-71.

[31] http://www.fchart.com/ees 